\title{
Gone but Not Forgotten: Death and Burial of Unidentified Individuals at the Bottom of the Social Scale in Dayton, Ohio
}

\author{
By Shelby Frideger Cornett \\ With contributions from \\ T. Joshua Keeton, Jesse Kidd, Danielle Linder, and Miriam Wilkins
}

\section{Introduction}

Woodland cemetery is a garden cemetery founded in 1841 in Dayton, Ohio and claims status as one of the United States' oldest garden cemeteries. $^{1}$ The concept of the garden cemetery was popularized during the Victorian Era. Garden cemeteries were far from the gloomy cemetery stereotype of today. They were places to take a stroll, have a picnic, and beautifully memorialize departed loved ones. In Landscapes of Memory Sarah Tarlow describes the multifaceted appeal of these garden cemeteries to the living. She also notes garden cemeteries were often displays of status and emotional identity for the dead. ${ }^{2}$ If opulent headstones indicate high socio-economic status, then burial without a headstone denotes the opposite end of the socio-economic ladder. In This Republic of Suffering Drew Gilpin Faust describes the Victorian notion of a "good death" as dying in the comfort of one's own home after making peace with god. ${ }^{3}$ As Faust applied this concept to death in the American Civil War, we will apply it to the case of Woodland's unknown burials. "Good Deaths" were not possible for people occupying lower economic echelons. This research examines the burials of unidentified individuals in Woodland Cemetery, whose burials reflect death and internment at the bottom of the social scale in turn of the century Dayton, $\mathrm{OH}$. The interred individuals examined in this study consisted almost entirely of men and children, whose bodies were found

\footnotetext{
1 "Woodland Cemetery and Arboretum," accessed October 30, 2017. http://www.woodlandcemet ery.org/.

2 Sarah Tarlow, "Landscapes of Memory: The Nineteenth-Century Garden Cemetery." European Journal of Archaeology 3 (2000): 217-39.

${ }^{3}$ Drew Gilpin Faust, This Republic of Suffering: Death and the American Civil War (New York: Alfred A. Knopf, 2008).
} 
under mysterious or unexplainable circumstances. How did these individuals die? Who were they in life, and why were their bodies never claimed? How were they buried in Woodland Cemetery and who was responsible for these burials? This topic is appealing initially for its mystery but careful archival research can provide answers to these questions, and reveal Daytonian attitudes toward the unidentified dead.

\section{Methods}

To identify the status of unknown individuals, data was collected from several primary sources found in the Wright State University Archives. The first being a book of Internment Records from May 1876 to September 1944. ${ }^{4}$ The book lists individuals by date of internment. The majority of entries detail the name, age, place of origin, and place of residence at death for each burial. Unidentified individuals were not listed by name, but a short description of the deceased occupied the name column. Descriptions ranged in age with terms including: unknown "foetus", unknown infant, unknown baby, and unknown man. The internment records attempted to estimate the ages of some unidentified men. Occasionally the records included details of where the body was found, the race, gender, and physical attributes of the deceased. Another primary source, a receipt ledger, provided a lesser quantity of information but aided in our understanding of who funded these burials and how much they cost. ${ }^{5}$ Microfilm of newspapers from the same time period proved to be a useful source for local historical context. Literature review established additional context. Two researchers took several pedestrian surveys of Woodland as a whole with specific attention to the City Lot which contained the majority of our subjects.

\footnotetext{
${ }^{4}$ Records of Internment, May 1876-September 1944, box 93, file 8. Special Collections and Archives, Wright State University Libraries.

${ }^{5}$ Record of Payments, 1874-1883, volume located in box 60, file 2. Special Collections and Archives, Wright State University Libraries.
} 


\section{Results}

Internment records revealed a total of 83 internments of unidentified individuals recorded between 1876 and 1940: 28 males, 1 female, and 3 individuals of unrecorded sex and age. The remaining 51 burials fell within the category of infant, fetus, or child. Children, and infants constitute the greatest number of unidentified individuals interred at Woodland. The chart below details the gender and age of subjects along with the location of discovery, if recorded.

\begin{tabular}{|l|c|c|c|c|}
\hline IDENTIFICATION & $\begin{array}{c}\text { TOTAL \# } \\
\text { (UNSPECIFIED) }\end{array}$ & CH\&D.RAILROAD & CANAL/RIVER & CITY \\
\hline MALE & $\mathbf{2 8}$ & 9 & 4 & 15 \\
FEMALE & $\mathbf{1}$ & - & -- & 1 \\
INFANT/FETUS/CHILD & $\mathbf{5 1}$ & -- & 12 & 39 \\
UNRECORDED SEX OR AGE & $\mathbf{3}$ & 2 & -- & 1 \\
\hline
\end{tabular}

Table 1: Location of discovery, gender, and age of unidentified 
The bar graph below is a depiction of the death rates by year of our population. Trends vary between slightly between the male and infant categories. Due to the minimal sample size of both female and unknown

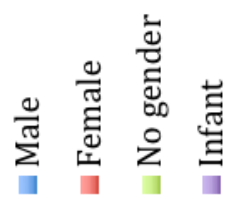

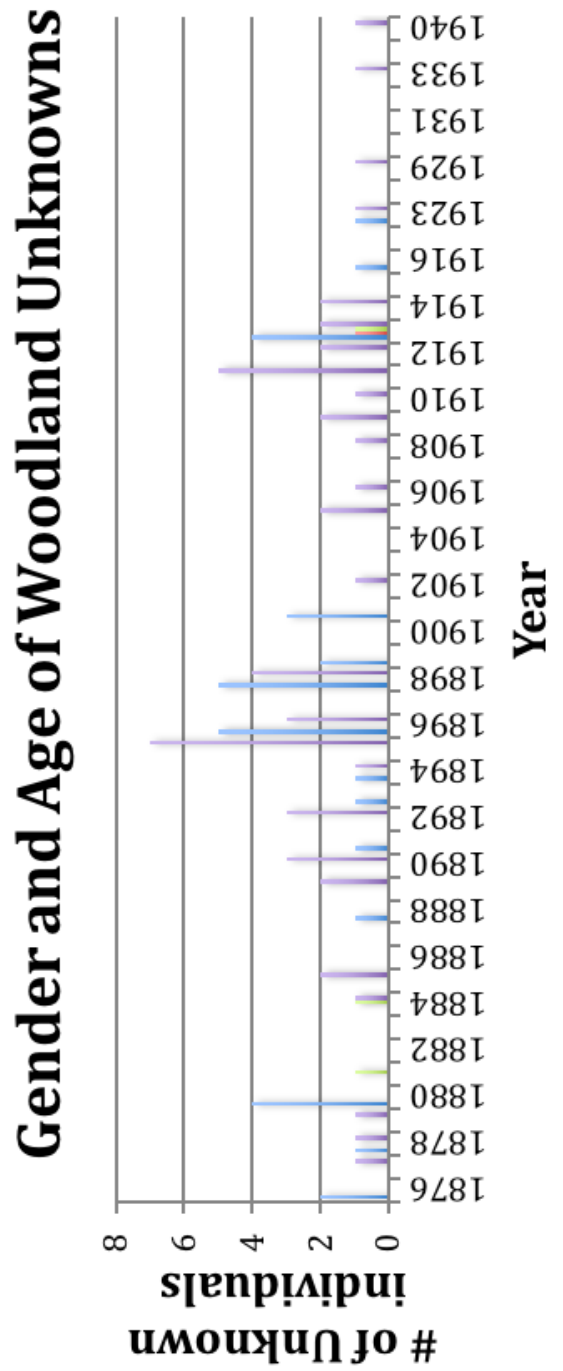


gender individuals, trends could not be established over time for these categories. First let us examine the death rates of Woodland's unknown men. Four years $(1880,1896,1898,1913)$ represent four spikes in the discovery of unidentifiable dead. The two highest spikes occur at the turn of the century. In contrast to male death rates infant mortality trends occur in two gradual increases followed by steady decline. Two peaks occur in 1895 and 1911.

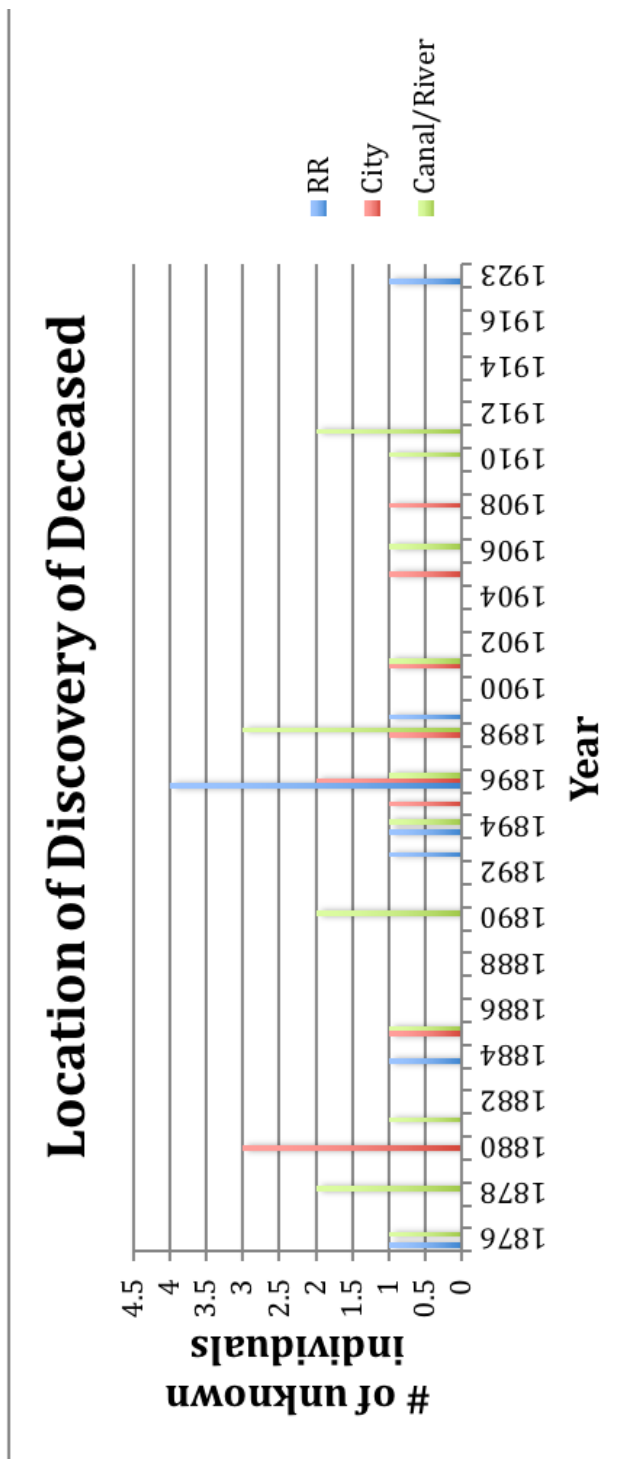


The second graph reveals trends in location of discovery through time. The location of discovery was not provided for any individuals after 1923, as such this graph ends at 1923 rather than extending to 1940 . The most frequently recorded location of death was in the city, then the canals or river, and lastly the railroad. Each of these locations spiked at differing times. 1880 experienced the highest number of deceased located in the city. Railroad deaths in this sample rose highest in 1896. Canal deaths spiked in 1898. By identifying these trends through time our research was better able to understand possible cultural influences on the status of and attitude toward Woodland's unidentified dead.

Newspapers reported high incidences of people being killed by railroads in Dayton, as is reflected in the internment record descriptions. Microfilm also revealed the dangers of driving on bridges in Dayton with a number of horse and carriage crashes resulting in people falling into the river and drowning. Literature review showed historical trends of infanticide and abortion. Unlike many examples found in literature review which showed unknown individuals and infants buried in mass graves, each of the burials at Woodland was a single occupant grave. The cemetery records helped identify that 77 of the 83 unidentified individuals were buried in the City Lot, or lot 126. Not a single headstone marked the burials of unknown individuals.

\section{Historic Context}

Dayton's first white settlers appeared in the spring of 1796; they had traveled north on the Great Miami River from Cincinnati. Dayton continued to grow in population with Ohio's statehood being established in 1803 . Construction of the Dayton-Cincinnati Canal in 1827, opened the city up to new opportunities in commerce. ${ }^{6}$ Dayton was also home to numerous

\footnotetext{
${ }^{6}$ Robert W. Steele, An Outline of the History of Dayton, Ohio, 1796-1896 (Dayton, OH: W. J. Shuey, 1896).
} 
inventors, including the Wright brothers. The first mechanical cash register, leaded gasoline, and LCD screen were all invented in Dayton. Paul Lawrence Dunbar, the influential poet also lived in Dayton during the turn of the century. ${ }^{7}$ Over Easter holiday 1913 the Great Dayton Flood devastated the city of Dayton leaving over three-hundred dead and thousands without homes. This flood spurned much innovation in the science of hydraulics. ${ }^{8}$ Dayton's status as an industrial powerhouse made it a central location in the war effort on the home front, producing tanks, planes, and soldiers. ${ }^{9}$

\section{Discussion}

This research speaks to the status, identity, and social relationships of the unidentified individuals interred at Woodland Cemetery. We demonstrate ways in which the community of Dayton chose to support, or not support such individuals in both antemortem and postmortem contexts. First let us examine the status of these individuals. What can be said about their perceived socioeconomic status after death? Does this research point to the possible socioeconomic status of the interred in life? Woodland Cemetery occupies the highest point in all of Dayton; the terrain of the cemetery is hilly. The City Lot is located in one of the lowest points of the cemetery and was used for individuals of low socioeconomic status who could not afford the more opulent burials on the cemetery hilltops. However, if this lot was for low cost burials who was paying for the burials of unclaimed individuals? These social outcasts had no one to claim their body and obviously could not pay for themselves. Examination of a receipt ledger resulted in 7 entries from 1876 to 1881, which correlated with a segment of the internment records. ${ }^{10}$ The City Infirmary and the City of

\footnotetext{
7 "Innovators," Ohio Humanities Council, http://daytoninnovationlegacy.org.

${ }^{8}$ Trudy E. Bell. The Great Dayton Flood of 1913. (Charleston, SC: Arcadia Pub., 2008).

9 "World War I Exhibit." Dayton History. https://www.daytonhistory.org/visit/things-to-seedo/world-war-i-exhibit/.

${ }^{10}$ Record of Payments, 1874-1883, volume located in box 60, file 2. Special Collections and Archives, Wright State University Libraries.
} 
Dayton paid for all 7 burials of unknown individuals found in the receipt ledger. The average cost of a burial in the City Lot at this time was $\$ 4.00$ for the burial of an adult, and $\$ 1.00$ to $\$ 1.50$ for the burial of a child or infant. At least in death these people were regarded as low status by the city who paid for their burials and by patrons of the cemetery who pass by these unmarked graves to this day with little or no regard. Despite their burial in Woodland, these graves are only identifiable through the historic paper trail. The importance of this research resides in the potential to tell the stories of these individuals who are long gone, with no one to visit their graves. Daytonians felt that a proper burial or "good death" .> was important for these individuals demonstrating a form of social responsibility. Did this responsibility also apply to unclaimed individuals before their death? What can be said about the lives of these individuals, before their mysterious demises?

The first step to understanding the lives of unknown individuals is identifying the possible circumstances of their deaths. As stated above, infants and children constituted the largest group found in our sample. This research proposes three possible explanations for the high proportion of infant deaths: susceptibility to disease, stillbirth or miscarriage, and unwanted pregnancies. The relatively large number of unknown infants buried in Woodland Cemetery hints at possible infanticidal practices in Dayton. It is probable that these children came from low socioeconomic homes and may have been stillborn, died from disease, poor sanitation, or malnutrition; and parents decided to dispose of the body or did not have enough money for a proper burial. However, a portion of the deceased infants were found in the river or canal, one was found in a hydraulic main, and another near the county fairgrounds. Though it is difficult to say for certain what circumstances surrounded infant deaths represented in Woodland Cemetery internment records, the fact that these infants were never claimed by any family and buried simply as "unknown infant" implies that their deaths were intentional, and if the death was not intentional the 
neglect or disposal of remains was. Notably the term "foetus" is used twice, implying that the child found was not carried to full term, which begs the question: where these "foetuses" the products of illegal or home abortions? Leslie Reagan shows that despite its criminal status abortion as an open secret, it was understood that unwanted pregnancies resulted in the woman getting an abortion and the man paying for it. ${ }^{11}$ Abortions were performed by doctors, but for a fee. Low socio-economic status individuals would not be able to afford such an abortion. It is also possible that the mothers were simply hiding miscarriages? ${ }^{12}$ One child was described as coming from the Children's House on Riegold St. It may be possible that there were institutional factors involved in the deaths of this child and possibly others.

Similar patterns of infant death existed concurrently in New York in the Five Points District, a location known for prostitution. ${ }^{13}$ Infant remains were excavated in the privies of known brothels. Though we did not investigate the intersection of prostitution with our sample, prostitution was historically present in Dayton. A pop-history article even discusses the "Queen of Dayton's red-light district" who is buried at Woodland Cemetery. ${ }^{14}$ Infanticide serves as a means of determining the economic environment for women, as well as their social status. When women are forced to work for wages that are not livable, infanticide becomes an "only option" for a starving mother. Or maybe a child potentially means losing a job in an unstable economic environment? This raises the question of how women were treated in Dayton, Ohio during the late $19^{\text {th }}$, and early $20^{\text {th }}$ centuries.

Though only one woman was represented in the sample, it can be safely assumed that all unknown children listed in the internment records had

\footnotetext{
${ }^{11}$ Leslie Jean Reagan. When Abortion Was a Crime: The Legal and Medical Regulation of Abortion, Chicago, 1880-1973 (Ann Arbor, MI: University Microfilms, 1992).

12 Aeron Hunt. 2006. "Calculations and Concealments: Infanticide in Mid-Nineteenth Century Britain." Victorian Literature and Culture 34 (1). Cambridge University Press: 71-94.

${ }^{13}$ Thomas A. Crist, "Babies in the Privy : Prostitution, Infanticide, and Abortion in New York City's Five Points District," Historical Archaeology 39 (2005): 19-46.

${ }^{14}$ Amelia Robinson, "What You Need to Know about the Queen of Dayton's Red Light...," accessed October 29, 2017, http://www.dayton.com/what-to-love/dayton-red-light-district/.
} 
mothers. These children could have died as the result of accident, miscarriage, abortion, or possibly infanticide. While it may be tempting to paint these women as bad mothers, due to the nature of the infants' deaths; literature review shows that the years between 1876 and 1944 were difficult for women. At this time, American gynecological practice was only in its infancy, a field dominated by men. The turn of the $20^{\text {th }}$ century saw the demonization of birth control and abortion by "professional" medicine and religious organizations, and the push for legislation on the matter began in force. Abortion occupied a grey legal area before this push and home abortion was not unheard of. Women were held solely responsible for the way their children turned out, and many women chose not to bare this burden stipulated by cultural standards. In fact, in 1898 the Michigan Board of Health estimated one of every three pregnancies ended in abortion in their Report of the Suffolk District Medical Society on Criminal Abortion and Ordered. ${ }^{15}$

Following infants and children, unidentified men accounted for 34 percent of our sample population. Though the largest portion of these men were found in an unspecified location, 4 men were found in the river or canal, and 9 were found near the railroad. The Cincinnati, Hamilton, \& Dayton Railroad (CH\&D) was specifically listed in the interment records and several news accounts from the period reported deaths being caused by this railroad. The Woodland interment records listed 9 unknown males killed by the "CH\&D" or "on railroad". No information was given on how they were killed only where they were found. Microfilm of Dayton Daily News and Dayton Weekly Paper revealed articles about "tramps" traveling the rails, and walking the tracks. These "tramps" were mainly Civil War veterans that kept to the rails as a form of transportation. ${ }^{16}$ This could help

\footnotetext{
${ }^{15}$ Carroll Smith-Rosenberg and Charles Rosenberg, "The Female Animal: Medical and Biological Views of Woman and Her Role in Nineteenth-Century America." Source: The Journal of American History 60 (1973): 332-56.

${ }^{16}$ Frank Tobias Higbie. Indispensable Outcasts: Hobo Workers and Community in the American Midwest (Urbana and Chicago: University of Illinois Press, 2003).
} 
explain their demise, and the prevalence of unknown individuals being found dead on the tracks, or in box-cars during this period. Illegal rail travel may have increased due to an economic downturn at the time which took place in 1873 , leading to the increase of tramps as described in Voices Education. ${ }^{17}$ If men were traveling the rails in Dayton at this time it is feasible that some of these men died from accidents, being hit by trains, or dying unexpectedly in a rail car. It is likely that these transient men would not have been known to the people of Dayton, offering one possible explanation as to why they were not identified after their deaths.

In addition to railways, bridges and canals also played an important role throughout the Midwest. 4 men and 12 infants were listed in the internment records as being found in the canals or rivers of Dayton. Today the use of bridges and canals is more regulated and the overall infrastructure and architecture of Dayton is much safer than it was historically. During this time canals and rivers regularly flooded, and bridges were poorly structured, narrow deathtraps on which many people lost their lives. Several accounts from historical newspapers describe carriages and buggies going over the sides of bridges and dumping their passengers overboard, or of individuals being run off the road or falling into the canal. Though these accounts offer some explanations of the circumstances surrounding the death of individuals found in canals and rivers, it does not explain why these people were not identified by family or acquaintances after they had been recovered. The Great Dayton Flood took place between March $21^{\text {st }}$ and $26^{\text {th }}$ of 1913 . This event is represented in the internment records by 5 individuals, buried within a week of the event. These unidentified individuals were the first to be followed by descriptions of their physical attributes; this was also the first mention of race. These descriptions were likely added to help identify the deceased in the wake of the chaos caused by the flood, but for unknown reasons no one came to claim them and they remained unidentified.

\footnotetext{
${ }^{17}$ Charles Baker. "Veterans, Tramps, \& the Economic Crisis of 1873 | Voices Education Project," accessed October 29, http://voiceseducation.org/node/208.
} 
Beyond the drive to satisfy a dark curiosity, why is this research important to our understanding of the Victorian Mid-West? Despite being unclaimed and unidentified by the people of Dayton, archival research of these individuals helped paint a more complete picture of their status, identity, and social relationships. This research speaks to community attitudes toward such individuals in both antimortem and postmortem contexts. Determining the socioeconomic status of the children and mothers would require further archival probing, but contextual research shows that reproductive rights were hotly contested then as they are now. The cultural climate at the time was a hostile environment to women of all socioeconomic statuses. In life, the status of men reflected in the internment records is likewise illusive; with the only hint being extracted from men who had been killed by the railroads. A life on the rails would explain their unknown status in death, and point to the low socioeconomic status associated with transient lifestyles. These deaths can also indicate possible criminal activity in Victorian Dayton, and reveal wider trends of accidental death due to poor infrastructure. The personal relationships of these individuals in life remain unknowable, but as they were unclaimed in death these relationships may have been strained or distant. The unknown burials of Woodland Cemetery reflect a sense of social obligation to the dead. These burials provided the departed dignity, but no status.

\section{Conclusions}

Infants, and by proxy mothers, and migrants interred at this time were treated in a way that reflected the importance of a proper burial for all people in Dayton during the late $19^{\text {th }}$ and $20^{\text {th }}$ centuries. This trend also fulfills Woodlands goal of being a nondenominational cemetery for all. While these unknown individuals were given burials, they were buried in unmarked graves in sections of the cemetery that are now all but forgotten. Daytonians felt a social obligation to these individuals in death that was likely not felt 
for those same individuals in life. Ironically, the unidentified dead were memorialized in the bureaucracy and paperwork of Dayton despite their lack of a physical memorial in the form of a headstone. Nationally women were renegotiating their societal roles, and subverting the strict Victorian standards. America was dealing with the repercussions of the Civil War, and would participate in both World Wars in the time covered by the Woodland internment records. While this research examined the status and gender of Woodland's unknown interments, future research might look at the intersection of race within this group. The possible connection between prostitution in Dayton and infanticide during the turn of the century also warrants closer investigation, as does the legal history of both prostitution and abortion in this area. Research on the Riegold St. Children's Home may turn up fruitful evidence of the influence of institutions on the child burials. Lastly bioarchaeological investigation of the City Lot could reveal more information about the interred. Nondestructive geophysical survey methods such as ground-penetrating radar and magnetometer survey of the City Lot could reveal buried headstones and the layout of graves without disturbing the ground. Ground-penetrating radar uses radar pulses which penetrate the ground, when the radar encounters a buried object, changes in material properties, or cracks, the radar is reflected, refracted, or scattered back to the surface and measured. This method is used to digitally map the subsurface of the research area. Magnetometer survey can be similarly used to measure variation in the earth's magnetic field, materials buried below the surface will cause disturbances in the earth's magnetic field which can then be digitally mapped. Destructive archaeological methods should be carefully considered in mortuary contexts as they involve the excavation of the grave and skeletal remains. If appropriate to the circumstances, archaeological excavation of skeletal remains can reveal marks of trauma and disease left on bone. Diseases such as Paget's disease, osteoporosis, arthritis, and bone tumors leave distinct marks on the bones which can been seen on skeletal remains. Fractures to bone if healed can reveal various injuries suffered by 
the individual in life. Unhealed bone fractures or perimortem injury could point toward a cause of death in these individuals.

The low social status of these individuals made a "good death" impossible. Laderman observes the low status of such burials; these people relied on charity in both life and death. ${ }^{18}$ These unknown people passed into the afterlife without ceremony and joined the silent ranks of the poor and departed before them. Though these individuals are gone and unidentified, careful investigation shows they are not entirely forgotten.

\footnotetext{
${ }^{18}$ Gary Laderman, The Sacred Remains: American Attitudes toward Death, 1799-1883. (New Haven: Yale University Press, 1999).
} 